\title{
INVENTÁRIO \\ NACIONAL \\ DE LIBRAS
}

INVENTARIO NACIONAL DE LIBRAS

NATIONAL INVENTORY OF LIBRAS

Ronice Müller de Quadros*

Universidade Federal de Santa Catarina

Jair Barbosa da Silva**

Universidade Federal de Alagoas

Rodrigo Nogueira Machado***

Universidade Federal do Ceará

Carlos Roberto Ludwig****

Universidade Federal do Tocantins

RESUMO: A documentação da Libras inclui o Inventário Nacional da Libras que integra o Inventário Nacional de Diversidade Linguística (INDL) com o objetivo de documentar a Libras de forma representativa no país. Este artigo apresenta o Inventário Nacional da Libras estabelecido, inicialmente, em Santa Catarina e a sua replicação nos estados de Alagoas, Ceará e Tocantins. Estes estados passam a ser agentes multiplicadores para a futura replicação do Inventário Nacional da Libras nos demais estados brasileiros garantindo-se, assim, a representação nacional do corpus da Libras estabelecido no escopo do INDL. Este artigo apresenta as diretrizes que norteiam a coleta, o arquivamento e a transcrição de dados, assim como as especificidades da constituição do corpus em cada estado brasileiro nesta primeira etapa de replicação do Inventário Nacional da Libras.

PALAVRAS-CHAVE: Libras. Documentação Linguística. Corpus de Libras.

\footnotetext{
* Professora e pesquisadora da Universidade Federal de Santa Catarina, no Departamento de Libras e pesquisadora do CNPQ. E-mail: ronice.quadros@ufsc.br.

** Professor de Linguística no Curso de Letras-Libras: licenciatura e no Programa de Pós-graduação em Linguística e Literaturada Universidade Federalde Alagoas, onde atuatambém como pesquisador. E-mail: jair.silva@fale.ufal.br.

*** Professor e pesquisador da Linguística no Curso de Letras Libras em licenciatura da Universidade Federal do Ceará e doutorando no Programa de Pós-Graduação em Linguística e Literatura da Universidade Federal de Alagoas. E-mail: roflam@gmail.com. 
RESUMEN: La documentación de la Lengua de Señas Brasileña (Libras) incluye el Inventario Nacional de Libras que forma parte del Inventario Nacional de Diversidad Lingüística (INDL) con el objetivo de documentar la Libras de manera representativa en el país. Este artículo presenta el Inventario Nacional de Libras establecido, inicialmente, en Santa Catarina y su réplica en los estados de Alagoas, Ceará y Tocantins. Estos estados se convierten en agentes multiplicadores para la futura reproducción del Inventario Nacional de Libras en otros estados brasileños, garantizando así la representación nacional del corpus de Libras establecido en el contexto del INDL. Este artículo presenta las pautas que orientan la recolección, archivo y transcripción de datos, así como las especificidades de la constitución del corpus en cada estado brasileño en esta primera etapa de reproducción del Inventario Nacional de Libras.

PALABRAS CLAVE: Libras. Documentación lingüística. Corpus de Libras.

ABSTRACT: The Libras documentation includes the National Inventory of Libras that integrates the National Inventory of the Linguistic Diversity (INDL) with the goal to document the Libras in a representative way in Brazil. This paper shows the National Inventory of Libras established, firstly, in Santa Catarina state, and then spreading to Alagoas, Ceará and Tocantins states. These states became charged, as well, to spreading even more that future replication of the National Inventory of Libras around the country to guarantee, then, the national representation of the Libras Corpus established in the scope of INDL. This paper presents the procedures that are common for the data collection, the documentation and annotation of the data, as the specificities of the corpus constitution in each Brazilian state in this first step of the replication of the National Inventory of Libras.

KEYWORDS: Brazilian Sign Language (Libras). Linguistic Documentation. Corpus of Libras.

\section{INTRODUÇÃO}

A documentação da Língua Brasileira de Sinais (doravante, Libras) integra o Inventário Nacional da Diversidade Linguística (INDL) que foi instituído pelo decreto presidencial 7387/10 como um instrumento de identificação, reconhecimento, valorização e promoção das línguas faladas no Brasil. Ele deve ser visto como o instrumento do Programa Nacional do Patrimônio Imaterial para dar conta das especificidades semióticas, socioculturais, políticas etc., das línguas faladas no Brasil, em contraponto às referências culturais contempladas por outros instrumentos do PNPI, como o Registro e o Inventário Nacional de Referências Culturais (IPHAN, 2012, p. 1).

Visto como um todo, o INDL pode ser definido como:

1. Um conjunto de informações sobre as línguas faladas no Brasil;

2. Uma base para se conhecer o universo linguístico nacional;

3. Uma política de reconhecimento patrimonial das línguas;

4. Uma política catalisadora de recursos e ações governamentais e não governamentais visando à salvaguarda das línguas.

(IPHAN, 2012, p. 1)

Em relação à Libras, iniciamos o Inventário Nacional da Libras para registrar esta língua usada nas comunidades surdas brasileiras. A Libras é uma língua nacional, reconhecida legalmente por meio da Lei 10.436/2002, e regulamentada pelo Decreto 5.626/2005. A documentação da Libras está sendo uma forma de organizar as informações sobre essa língua e mapear os aspectos linguísticos que a constitui. Além disso, tem sido uma forma de apresentar um conjunto de dados sobre esta língua à comunidade surda e acadêmica para fins de interesse político, social, cultural, educacional, linguístico e científico.

No Brasil, o estudo científico da Libras teve início na década de 80, com os trabalhos importantes da linguista Lucinda Ferreira Brito (UFRJ) e a inclusão do Grupo de Trabalho Linguagem e Surdez, na Associação Nacional de Pós-Graduação e Pesquisa em Letras e Linguística (ANPOLL). Apesar disso, no desenrolar das décadas de 80 e 90, o estudo da Libras permanece ainda bastante marginal ao interesse da maioria dos pesquisadores brasileiros. Foi apenas na década de 2000-2010 que pudemos testemunhar o início do processo de consolidação do campo de investigação da Libras no Brasil. Com a promulgação de duas leis relativas à Libras - a lei n. 10.436, de 2002, que a reconhece como língua da comunidade surda brasileira, e o Decreto n. 5626, de 2005, que a regulamenta - 
pudemos observar uma série de avanços importantes para o campo no Brasil: a criação de cursos de Letras-Libras nas modalidades presencial e a distância, atendendo à necessidade de formação de professores e intérpretes de Libras em todo o país; a criação do exame de certificação nacional de proficiência em Libras (PROLIBRAS), com o intuito de certificar professores e intérpretes de Libras já atuantes na área, mas ainda carentes de uma formação; e a intensificação da produção científica voltada para a Libras em nível de pós-graduação, tanto lato sensu quanto stricto sensu, com destaque para o ingresso crescente de pessoas surdas em programas de mestrado e doutorado - um importante marco na história de nosso país.

O estudo científico da Libras, portanto, passa hoje por uma fase decisiva. A demanda acadêmica e social por conhecimento relativo à Libras é grande, mas o campo de investigação tendo como foco essa língua ainda está se estruturando. De modo geral, observa-se no Brasil a mesma dificuldade enfrentada no campo de pesquisa com línguas de sinais ao redor do mundo: há uma enorme variação e inconsistência nos critérios de registro, documentação, análise e apresentação dos dados de línguas sinalizadas à comunidade acadêmica (MILLER, 2001). Esse quadro dificulta um debate rico, empiricamente fundamentado, sobre os diferentes aspectos linguísticos das línguas de sinais, bem como a utilização desse conhecimento em vários âmbitos aplicados, como é o caso da educação de surdos, o ensino de Libras como L1 e L2, a formação de intérpretes de Libras, traduções literárias para a Libras, dentre outros.

Não por acaso, a sistematização dos procedimentos de coleta, documentação e recuperação de dados e metadados de línguas de sinais tem adquirido grande relevância mundial nas últimas décadas (e.g. CRASBORN; VAN DER KOOIJ; MESCH, 2004; EFTHIMIOU; FOTINEA, 2007; HANKE, 2000; LEESON; SAEED; BYRNE-DUNNE, 2006; LEITE, 2008; SCHEMBRI, 2008, CHEN-PICHLER et. al., 2010; LEITE; QUADROS, 2014; QUADROS, 2016; QUADROS et. al., 2019). Com a Libras, não poderia ser diferente. A criação de corpora de Libras e a sistematização de seu processo de construção está contribuindo de diferentes maneiras para a consolidação do campo teórico e aplicado relativo à Libras no Brasil.

No sentido de fomentar ações voltadas para políticas públicas no campo linguístico e educacionais, de uma forma mais direta, a pesquisa do Inventário Nacional de Libras começa a disponibilizar para os órgãos públicos, os seguintes materiais:

1. um corpus da Libras empiricamente abrangente e teórico-metodologicamente bem fundamentado, representando, também, um inventário da Libras das regiões metropolitanas de Florianópolis, do Estado de Santa Catarina; Maceió, do Estado de Alagoas; Fortaleza, do Estado do Ceará; e Palmas, Estado do Tocantins, de forma gratuita e online, a outros pesquisadores da Libras e a profissionais que atuam com pessoas surdas e que desejem utilizá-lo para fins variados, especialmente para uso na educação (QUADROS et al., 2020);

2. diretrizes para a constituição de corpus de Libras em futuras pesquisas, particularmente no que tange ao registro, à documentação e à recuperação de dados para fins de análise linguística;

3. disseminação à comunidade acadêmica as alternativas tecnológicas de que hoje dispomos para fundamentar empiricamente as pesquisas com Libras de uma maneira consistente;

4.

5. um importante registro linguístico, histórico e cultural da vida das pessoas surdas de quatro regiões do país, contribuindo para o processo de inclusão social na sociedade brasileira, podendo, posteriormente, ser estendido a outras regiões do país.

\section{HISTÓRICO DA DOCUMENTAÇ̃̃O DE LIBRAS}

A documentação da Libras começou a ser constituída em $1995^{1}$. Este material envolve diferentes projetos compreendendo dados de fontes diversas e diretrizes para o registro dos dados e metadados nessa língua. O primeiro deles documenta dados de estudos longitudinais com crianças surdas filhas de pais surdos adquirindo a Libras. Posteriormente, foram incluídas crianças surdas, filhas

\footnotetext{
${ }^{1}$ A documentação da Libras está sendo constantemente alimentada e encontra-se disponível no Portal de Libras, [https://libras.ufsc.br] no link do corpus, que pode ser acessado diretamente em [http://www.corpuslibras.ufsc.br/]. Os dados disponibilizados envolvem projetos que contaram com diferentes fontes de fomento: CNPQ, CAPES, IPHAN e NIH.
} 
de pais ouvintes; crianças surdas com implante coclear, filhas de pais surdos e pais ouvintes; e crianças ouvintes, filhas de pais surdos (Codas).

O Banco de Dados de aquisição da Libras atingiu maturidade metodológica, pois desenvolveu uma série de ferramentas que possibilitaram a organização dos dados para a realização das análises. Os dados estão organizados de tal forma a viabilizar pesquisas por terceiros, contando sempre com as devidas precauções observadas pelo Comitê de Ética. O acesso aos dados começa a ser mais amplo, mas se mantém restrito, no sentido de resguardar a visualização dos vídeos de crianças. Para isso, o Comitê de Ética exigiu cartas de consentimento que especificassem a permissão explícita dos pais e, quando possível, da própria criança para o acesso irrestrito a demais pesquisadores. $\mathrm{O}$ acesso irrestrito enriquece o próprio banco de dados e as produções de pesquisa que se multiplicam, pois permite a inclusão de transcrições adicionais, bem como de análises dos dados que constituem as pesquisas no próprio banco de dados, consolidando o Corpus de Libras de aquisição da linguagem. A metodologia estabelecida no escopo deste banco de dados serviu de referência para os materiais que estão sendo usados no Inventário Nacional de Libras que integra o Corpus de Libras (QUADROS, 2016). Esse inventário tem o objetivo de estabelecer a documentação da Libras em âmbito nacional e já conta com dados coletados da grande Florianópolis, Santa Catarina; da grande Maceió, Alagoas; da grande Fortaleza, Ceará; e da grande Palmas, Tocantins ${ }^{2}$. Essa coleta de dados objetiva ser replicada em todo o Brasil para o estabelecimento de um Corpus da Libras com dados que permitam análises comparáveis da Libras de diferentes regiões do país. A metodologia usada para o Inventário Nacional de Libras compreende interações de surdos em pares divididos em três grupos, por idade e por gênero. Todos os procedimentos para a coleta dos dados, organização dos dados e metadados, transcrição dos dados foram aplicados e ajustados para serem usados em todo o país e permitir dados em Libras comparáveis entre os surdos de diferentes regiões do país. Assim, com os dados seguindo os mesmos procedimentos metodológicos, teremos condições de analisá-los para identificar os fatores contextuais que influenciam a variabilidade da Libras, explicando os fenômenos linguísticos estudados.

A documentação de Libras também inclui dados do Libras Acadêmico, que compreendem produções do Exame ProLibras e do Curso de Letras Libras EAD da Universidade Federal de Santa Catarina. O Libras Acadêmico inclui a publicação de vários materiais produzidos pelos alunos durante a oferta do curso, especialmente trabalhos produzidos em Libras e literatura em Libras. Neste caso, os materiais disponibilizados contam com a permissão direta de ex-alunos e dos participantes das atividades do Exame Prolibras. Os materiais coletados foram catalogados e publicados no Corpus de Libras Acadêmico no respectivo estado do polo no qual o aluno estava frequentando o curso. Esses materiais são muito úteis para alunos surdos, alunos interessados em Libras, professores de Libras e educadores bilíngues. Esta documentação está sendo complementada por meio do Inventário Nacional de Libras, com o financiamento do Ministério da Cultura, pelo IPHAN, por meio de uma parceria com o Instituto de Políticas Linguísticas (IPOL) e a Universidade Federal de Santa Catarina.

Além destes dados, a documentação integra a Antologia de Poemas em Libras. Segundo Machado (2017), uma antologia de línguas de sinais constitui uma forma de registro da cultura surda por meio de produções poéticas. Essa antologia compreende poemas produzidos por surdos com diferentes estilos objetivando representar a produção poética em Libras e em breve estará disponível no Corpus de Libras.

Além disso, os dados do Inventário da Libras são utilizados para alimentar o Banco de Sinais da Libras (Signbank Libras). Trata-se de um banco de dados do léxico da língua brasileira de sinais com variantes da Libras dos estados que já realizaram coleta de dados e, no momento, realizam a transcrição dos dados (UFSC, 2020).

Novos projetos podem passar a compor a documentação da Libras, tornando-o mais amplo e variado e compreendendo uma documentação da Libras para ser acessada para diferentes fins, entre eles, para fins históricos, para o ensino e para a pesquisa.

\footnotetext{
${ }^{2}$ O Inventário de Libras da Grande Florianópolis está sob a coordenação de Ronice Müller de Quadros e contou com o financiamento do CNPQ (Processos 303725/2013-3 e 471355/2013-5) e o Inventário de Libras de Maceió está sob a coordenação de Jair Barbosa da Silva com o financiamento do CNPQ/Universal (460589/2014-8). Os Inventários da Grande Fortaleza, da Grande Palmas, da Grande Maceió também contam com o financiamento no escopo da Documentação da Libras (CNPQ Processo 440337/2017-8). O Inventário de Libras da Região de Palmas, sob coordenação de Carlos Ludwig, também possui apoio financeiro da Capes, projeto Procad-Amazônia, em parceria com a UFSC (Processo 23038.005350/2018-78).
} 
Os dados compreendidos na documentação da Libras incluem também arquivos de transcrição e anotação dos dados. O objetivo das transcrições e anotações é permitir a análise linguística sistematizada. Para isso, foram estabelecidas normas para a realização dessas transcrições e anotações objetivando atingir consistência que permita aos pesquisadores compreender os registros realizados, bem como comparar os dados em análise. A seção que descreve a metodologia apresentará os estudos já realizados sobre transcrições e anotações de línguas de sinais e, posteriormente, explicitará o processo de estabelecimento destas normas para o Corpus de Libras, especialmente, para o Inventário Nacional de Libras que tem servido de fonte para a constituição das gramáticas da Libras (QUADROS, 2017).

\section{DA FORMAÇÃO DOS PESQUISADORES COLABORADORES}

Os pesquisadores colaboradores do Inventário Nacional da Libras passam por um processo de formação que envolve tanto aspectos teóricos quanto aspectos práticos do trabalho de constituição de corpus.

Inicialmente, o pesquisador coordenador da pesquisa, juntamente com o pesquisador local surdo dos estados de Alagoas, Ceará e Tocantins estiveram na UFSC em para participar da formação que foi realizada por meio da exposição e prática efetiva de todas as etapas do processo de constituição do corpus (coleta, arquivamento e transcrição).

\section{DA COLETA DOS DADOS}

A coleta de dados tem seguido um mesmo padrão metodológico para os três estados envolvidos a fim de que se possam tornar os dados comparáveis e qualitativamente equivalentes. Desse modo, os recursos tecnológicos para coleta, tratamento (edição e transcrição) e armazenamento serão os mesmos, assegurando-se, no final, um corpus homogêneo com registros consistentes da Libras, com vistas às pesquisas nas áreas de Linguística, Literatura, Cultura, dentre outras. Os dados coletados a partir desta metodologia integram os estudos linguísticos da Libras.

A fim de compor o quantitativo de participantes envolvidos na pesquisa, segue-se a descrição abaixo:

1. Um professor pesquisador ligado a cada Universidade envolvida;

2. Um pesquisador local surdo (uma liderança surda representante da comunidade surda);

3. 36 surdos das capitais onde as Universidades estão alocadas, os quais serão gravados em duplas, formando, assim, 18 entrevistas.

O pesquisador local surdo apresenta o seguinte perfil para se engajar no Projeto: i) nato da capital, ou residir e conviver com a comunidade surda local por no mínimo 10 anos; ii) pessoas extrovertidas e articuladas, de preferência com experiência acadêmica em nível de graduação ou pós-graduação; iii) pessoas com conhecimento tecnológico básico para as finalidades do projeto e com facilidade de acesso diário a computador e internet. Por outro lado, para ser selecionado como informantes da pesquisa, os sujeito têm de atender aos seguintes critérios: i) ser nato do estado da capital onde o projeto estiver em desenvolvimento ou nela residir há pelo menos 10 anos; ii) ter adquirido a Libras em idade pré-escolar (até 7 anos de idade), ou no mínimo por mais de 7 anos (tempo de exposição à língua), ou com proficiência notória na comunidade; iii) a dupla deverá ser formada por pessoas íntimas entre si (amigos ou parentes), preferencialmente do mesmo gênero e faixa etária. Além disso, é importante que, dentre as 18 duplas a serem entrevistadas, o pesquisador local busque selecionar duplas com perfis variados, considerando critérios tais como: iv) surdos que representem aproximadamente 3 diferentes gerações, incluindo jovens (até 30 anos), adultos (entre 30 e 60 anos) e idosos (a partir de 60 anos); v) surdos homens e mulheres; vi) surdos com diferentes graus de escolarização (ensino fundamental, ensino médio e ensino superior completo). Por fim, só serão incluídos como informantes no projeto aqueles surdos que consentirem sem quaisquer restrições a todas as condições de uso e distribuição de suas imagens, tal como será definido no Termo de Participação em Pesquisa. Para a coleta dos dados, os informantes vão ao estúdio montado na Universidade ou os pesquisadores vão aos espaços onde os informantes surdos se sintam mais confortáveis para serem gravados - associações, escolas etc. Nesse sentido a equipe de coleta de dados deve envolver: um (1) pesquisador colaborador da equipe de coordenação e um técnico. A este cabe a montagem e 
desmontagem do estúdio, supervisão técnica do processo de gravação e arquivamento dos dados; àquele, a tarefa de condução da entrevista.

O estúdio conta com 4 filmadoras para captar os informantes em diferentes tomadas, o que se faz necessário para uma análise minuciosa dos articuladores manuais e não manuais em contextos conversacionais (Leite, 2008). Cada participante tem acesso a 1 notebook, onde assiste aos estímulos que servirão de base para a sua produção, e o pesquisador dispõe de um terceiro notebook para manipulação dos estímulos e registro de informações pertinentes às sessões de gravação. Os postes de luz, bem como o tecido de lycra, que servirá de plano de fundo das gravações, têm como objetivo garantir condições ótimas de visualização dos sinalizadores.

As câmeras são posicionadas de acordo com configurações espaciais previamente testadas e planejadas, o que irá variar de acordo com a atividade que está sendo gravada (e.g. eliciação individual $v s$., conversação livre). Em particular, em cada atividade deverá atentar-se para a necessidade de se ter pelo menos uma tomada com foco no rosto do sinalizador e uma tomada com foco no espaço de sinalização mais geral.

As entrevistas com os informantes são compostas pelas seguintes atividades, que totalizam aproximadamente 2 horas por entrevista:

i) atividade de descontração e entrevista de vida (30 minutos): por meio de uma entrevista semiestruturada e semiaberta, o pesquisador buscará eliciar do informante relatos pessoais, envolvendo questões tais como: a história do seu sinal, a sua história de aquisição da Libras e de participação na vida da comunidade surda local, a sua relação com a língua portuguesa e a Libras em termos de usos e atitudes, o(s) acontecimento(s) de maior impacto em sua vida particular, e suas aspirações pessoais e profissionais;

ii) atividade de eliciação de narrativas (20 minutos): o participante irá recontar três narrativas que já foram utilizadas em diversos estudos linguísticos e, portanto, poderão ser utilizadas em pesquisas comparativas com outras línguas orais e línguas de sinais: a Pear Story; a Frog: where are you?; e a Canary Row, de Tweety \& Sylvester;

iii) intervalo de 20 minutos para descanso;

iv) atividade de eliciação gramatical e lexical (30 minutos): o participante será apresentado a estímulos criados especificamente para a eliciação de construções gramaticais e itens lexicais da Libras, a serem adaptados do projeto de corpus da língua de sinais alemã (NISHIO et al., 2010);

v) conversação (até 20 minutos): a dupla será deixada a sós no estúdio para conversar, ou de forma livre ou sobre um tema do cotidiano a ser oferecido pelo pesquisador como estratégia de estímulo.

As entrevistas devem ser desenvolvidas de modo a garantir o registro de expressões culturais verbais, amostras de palavras e elementos gramaticais, vocabulário específico à realidade cultural, empréstimos, frases ilustrativas de elementos da gramática, demonstração de variedades dialetais e elementos que singularizam a língua tipologicamente dentro da região e universalmente. Além disso, devem ser consideradas formas de documentação da Libras em situações cotidianas, o que exigirá o desenvolvimento de uma metodologia adequada para filmagem em ambientes externos não controlados.

Além destas 2 horas de coleta de dados em estúdio, os participantes são filmados em interações espontâneas por 30 minutos dentro da Associação de Surdos local, totalizando 2 horas e 30 minutos de dados (150 minutos) por dupla, considerando 18 duplas, perfazendo 45 horas (2.700 minutos).

\section{DA TRANSCRIÇÃO}


Primeiramente, os pesquisadores colaboradores, pesquisador local surdo, estudantes de iniciação científica e demais envolvidos na pesquisa passaram por rigoroso processo de formação, o qual foi feito em parceria com a UFSC, a fim de que se possa fazer transcrições de boa qualidade, haja vista que é o processo que mais demanda tempo, atenção e acuidade.

É importante salientar que a transcrição de línguas de sinais, uma vez que não se dispõe de um sistema especificamente adaptado de forma plena para transcrição, demanda bastante tempo, razão por que os dados que serão recolhidos terão sua transcrição total realizada sempre em função da mão de obra que se disponibilize para esse fim (bolsistas, pesquisadores). Dada a complexidade de transcrição de Libras, os dados do Inventário Nacional de Libras se atém em apenas a seis trilhas do ELAN, no primeiro momento: a) glosagem de sinais manuais da mão direita, b) a glosagem de sinais manuais da mão esquerda; ambas de forma integrada ao Identificador de Sinais; c) tradução de enunciados para o português, d) a tradução das glosas para o inglês da mão direita; e) a tradução das glosas para o inglês da mão esquerda; e f) a tradução de enunciados do português para o inglês.

A transcrição é feita com base num arquivo: modelo de transcrição do ELAN desenvolvido pela equipe do Projeto matriz (UFSC) e que é introduzido aos pesquisadores colaboradores ao longo de sua formação. Ainda que o arquivo-modelo de transcrição possibilite a transcrição de todos os articuladores manuais e não manuais necessários à descrição da Libras (ver Leite, 2008), os pesquisadores colaboradores deverão operar apenas com as trilhas correspondentes aos principais aspectos mencionados no parágrafo anterior, reservando a transcrição de outros articuladores para um momento subsequente deste trabalho. Essa opção é viável, tendo em vista que o ELAN permite a visualização apenas das trilhas de interesse imediato, as demais permanecendo no arquivo de forma oculta.

Todas as transcrições passam por um processo de validação. Para isso, membros do projeto com experiência em transcrição realizam uma segunda transcrição em amostras estatisticamente significativas dos dados coletados em outros estados, com fins de comparação com as transcrições originais. Esse processo é realizado periodicamente a fim de avaliar o processo de transcrição e introduzir ajustes quando necessário. Além disso, um pesquisador é encarregado de revisar a transcrição original em busca de inconsistências com relação às convenções de anotação desenvolvidas no projeto. No âmbito desta etapa do Inventário Nacional de Libras, foi realizado um processo de validação entre os três estados em conjunto com a UFSC. O resultado deste processo de validação determinou ajustes no manual de transcrição da Libras.

\section{INVENTÁRIO NACIONAL DE LIBRAS: ALAGOAS, CEARÁ E TOCANTINS}

A partir do modelo metodológico desenvolvido em Santa Catarina com diretrizes para a constituição do Inventário Nacional da Libras, a coleta, o arquivamento e as transcrições estão sendo replicados gradativamente no Brasil para a constituição de um corpus nacional da Libras representativo. Nesta primeira replicação, os estados de Alagoas, Ceará e Tocantins integraram o Inventário Nacional da Libras.

A seguir apresentamos o Inventário Nacional da Libras nos estados de Alagoas, Ceará e Tocantins.

\subsection{INVENTÁRIO DA LIBRAS DE ALAGOAS}

Em 2014, quando o Curso de Letras-Libras da Universidade Federal de Alagoas estava em fase de implantação, os coordenadores do Curso, professores Jair Barbosa da Silva (coordenador) e Humberto Meira de Araújo Neto (vice-coordenador), fizeram uma visita técnica à UFSC por ser esta a Universidade referência no Brasil nesse tipo de curso. A equipe da UFAL foi recebida pela coordenação do Letras-Libras da UFSC, professora Karin Strobel, e pela pesquisadora Profa. Dra. Ronice Müller de Quadros, a qual apresentou-nos, dentre outros projetos, o Inventário da Libras da grande Florianópolis. Coincidentemente, o Edital/Universal/CNPq/2014 estava com chamada aberta. Encantados com o projeto da UFSC e cientes de que a pesquisadora gostaria de que ele fosse replicado em todo o país, não hesitamos em submeter um projeto para financiamento pelo CNPq, nos mesmos moldes do da UFSC. O projeto da UFAL foi aprovado, processo (460589/2014-8), tendo os recursos disponibilizados em 2015 e 2016, o que retardou o início da coleta de dados. Outro fator que causou atraso na recolha dos dados foi a mudança de prédio 
do curso de Letras-Libras (antes instalado em prédio provisório e, a partir de 2018, passou a ter sede própria na Universidade).

Entre o segundo semestre de 2014 e primeiro semestre de 2015, foi montada uma equipe formada por professores e alunos do LetrasLibras para a execução do projeto. Por meio da chamada do PIBIC/UFAL, ciclo 2014/2015, selecionamos dois alunos de iniciação científica, sendo um bolsista e uma colaboradora. O bolsista, Sergio José da Silva, aluno surdo do Letras-Libras, era também o nosso surdo de referência, conforme modelo do projeto matriz (UFSC), para intermediar junto à comunidade surda da grande Maceió os contatos e convites aos surdos participantes do projeto. Em março de 2015, o coordenador executivo do projeto, professor Dr. Jair Barbosa da Silva, juntamente com Sergio José da Silva participaram de uma formação por dois dias na UFSC sobre a coleta, a transcrição e guarda de dados do projeto, conforme protocolos do projeto já em andamento da UFSC.

Ainda em 2015, formamos a equipe da UFAL para a execução do projeto em termos científicos, técnicos, tecnológicos e éticos e, então, começamos a coleta dos dados, fazendo todos os testes relativos à qualidade de luz, de imagem, ajustes gerais nos instrumentos de coleta, por meio de uma coleta-piloto. Concluída essa etapa, começamos a coleta com o primeiro grupo etário de informantes (de 18 a 30 anos). Em 2016 e 2017, a equipe de execução do projeto em Maceió ganhou novo integrantes, bolsistas e colaboradores, o que deu celeridade ao processo de coleta dos dados e início das transcrições e armazenamento, tendo esse processo sido interrompido pela mudança de espaço físico do curso de Letras-Libras para prédio próprio, cuja efetivação foi concluída apenas abril de 2018, quando retomamos as atividades práticas do projeto, especialmente, o término das coletas.

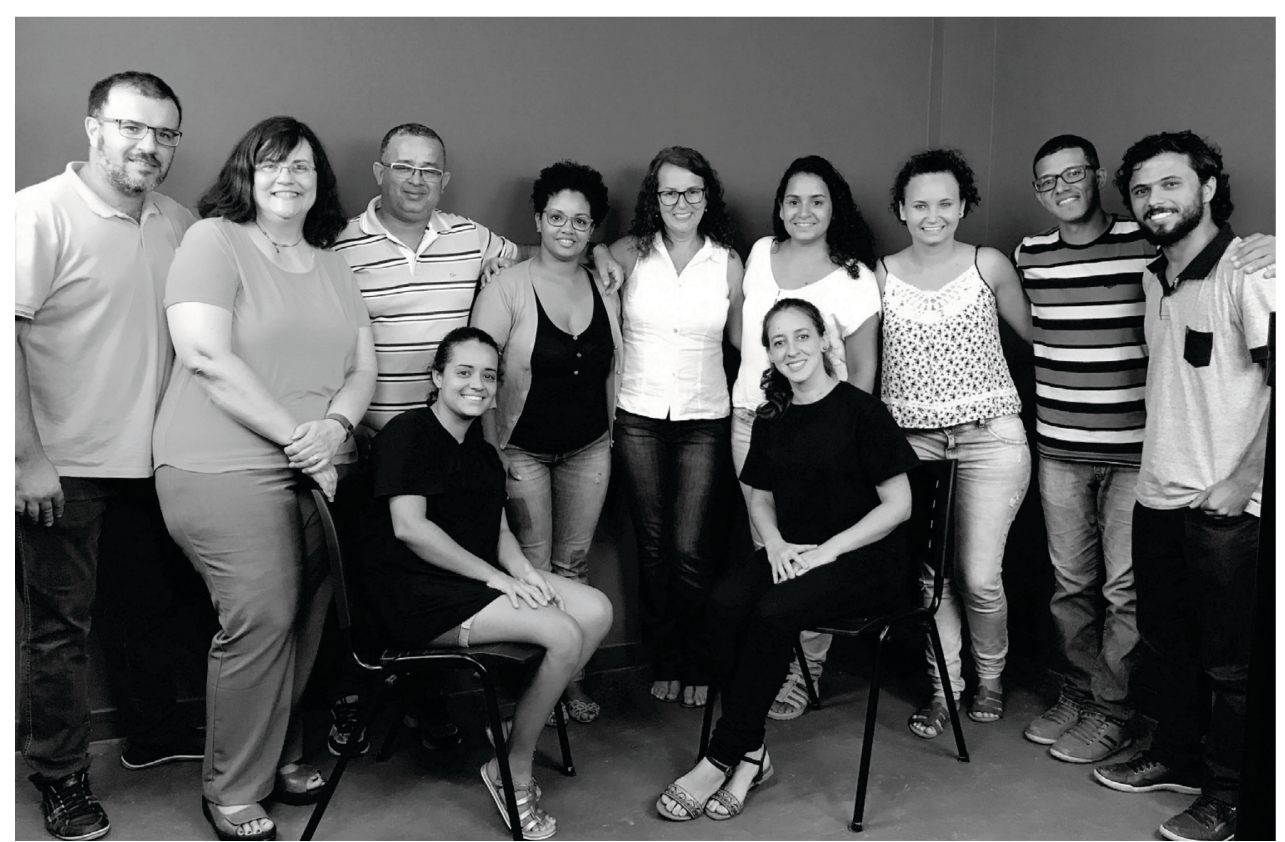

Figura 1: Visita técnica das pesquisadoras Ronice Müller de Quadros e Diane Lillo-Martin ao Projeto da UFAL - 2017

Fonte: Inventário da Libras da Grande Maceió (2017)

A equipe integrante do projeto atuou em diversas atividades - formação inicial e contínua, leituras, pré-testes para as coletas, tradução, interpretação e gravação do TCLE em Libras, contato com os informantes, recepção dos informantes, preparação do estúdio para coletas, coletas, edição dos vídeos, transcrição dos dados, validação dos dados e armazenamento dos dados em dispositivos físicos e no servidor da UFSC. Constituíram a equipe de trabalho alunos e professores da UFAL, em grande parte vinculados ao Letras-Libras, a quem agradecemos muito sinceramente e nominalmente, pois se trata de um trabalho cuja realização só acontece no coletivo:

Jair Barbosa da Silva - Coordenador executivo do projeto e pesquisador;

Bruno Silva Pedra da Rocha - Graduando do curso de Letras-Libras, surdo, colaborador PIBIC de 2017 - 2018;

Daniel Cícero dos Santos Barbosa - Graduando do curso de Letras-Libras, surdo, colaborador PIBIC de 2016 - 2017;

Elétrica Pinheiro da Silva - Graduanda do curso de Letras-Francês, colaboradora PIBIC de 2014 - 2015; 
Evely de Souza Mendonça Silva - Graduanda do curso de Letras-Libras, surda, colaboradora PIBIC de 2016 - 2018 ;

Ewerton Douglas Canuto de Albuquerque - Graduando do curso de Letras-Libras, surdo, bolsista PIBIC/CNPq de 2015 - 2019 ;

Humberto Meira de Araújo Neto - Professor colaborador e pesquisador;

Jéssica Nobre Cedrim Lucena - Graduanda do curso de Letras-Libras, surda, colaboradora PIBIC de 2015 - 2017;

Karoline Morgana Gomes Nicácio Araújo - Graduanda do curso de Letras-Libras, surda, colaboradora PIBIC/CNPq de 2018 2020;

Lívia Andrade da Conceição - Professora surda colaboradora;

Magda Souto Rosa do Monte - Professora surda colaboradora;

Maiara Silva Santos - Graduanda do curso de Letras-Libras, surda, bolsista PIBIC de 2015 - 2020;

Raimundo Nonato Maia Júnior - Graduando do curso de Letras-Libras, colaborador, de 2016 - 2018 ;

Sergio José da Silva - Surdo de referência, graduando do curso de Letras-Libras e bolsista do PIBIC de 2014 - 2018.

Os dados de Alagoas foram coletados com informantes surdos da região metropolitana de Maceió, a qual é formada por treze municípios, a saber: Maceió (capital), Paripueira, Barra de Santo Antônio, Murici, Messias, Rio Largo, Atalaia, Pilar, Satuba, Santa Luzia do Norte, Coqueiro Seco, Marechal Deodoro e Barra de São Miguel, seguindo-se o mesmo protocolo da UFSC em termos de perfil dos informantes quanto ao processo aquisicional da Libras ou ao contato com essa língua e com a comunidade surda a que pertence, como descrito na seção 4. Embora o projeto preveja a presença de surdos da região metropolitana de Maceió, a maior parte dos que compuseram a coleta de dados são de Maceió, fato que se deve, sobretudo, à maior facilidade de deslocamento para o locus da coleta, o LabLibras (Laboratório de Libras), na UFAL.

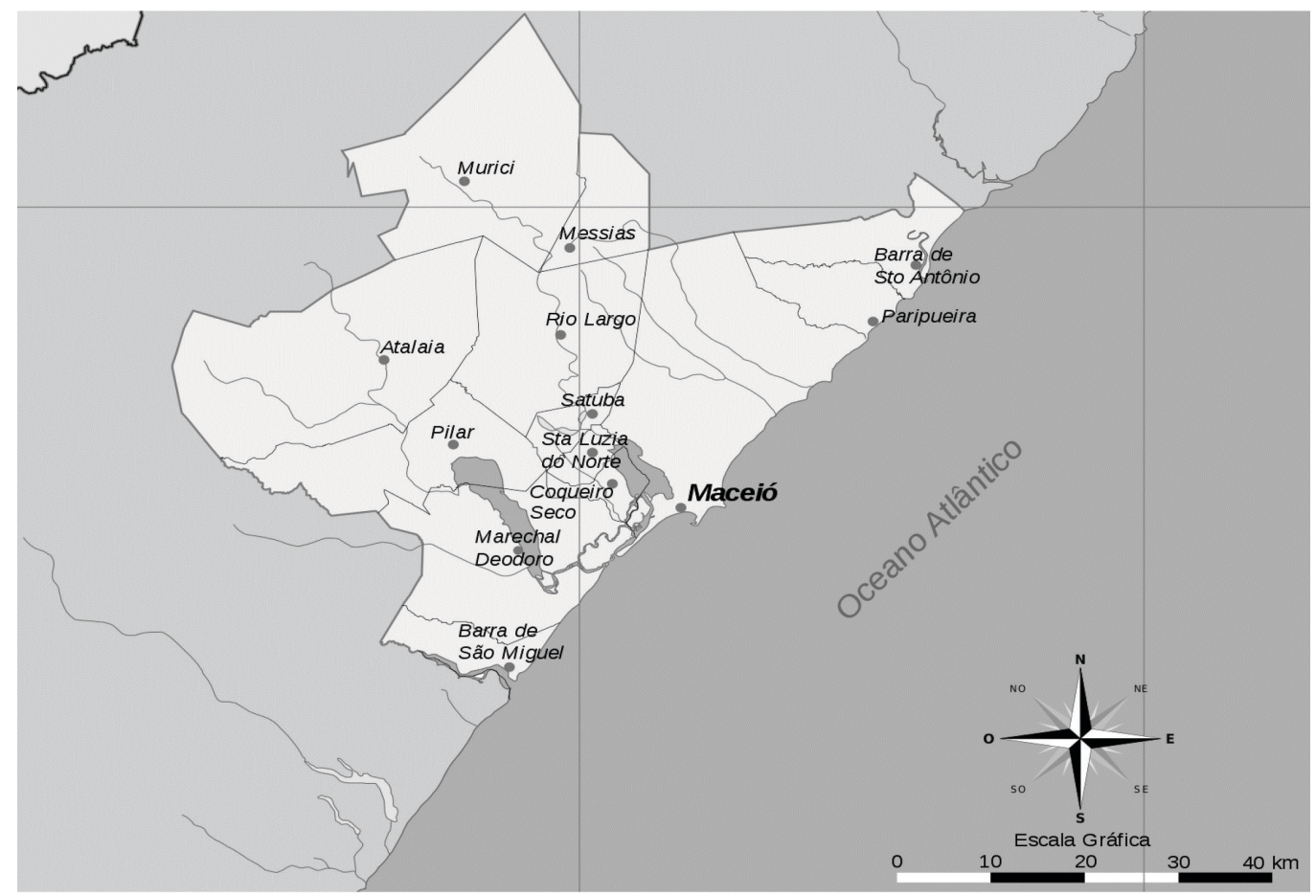

Figura 2: Mapa da Região Metropolitana de Maceió - Alagoas

Fonte: WIKIPEDIA (2020)

Em 2019, dois importantes processos se deram: a) reunião com o grupo do Inventário Nacional de Libras em maio de 2019, na UFAL, com o objetivo de fazer a validação dos dados do projeto, com a presença da Professora Ronice Müller de Quadros (UFSC), coordenadora geral do projeto, do professor Carlos Roberto Ludwig (UFT), coordenador executivo do projeto do Tocantins, do professor Rodrigo Nogueira Machado (UFC), coordenador executivo do projeto do Ceará, e da professora Ana Regina Campello (INES), coordenadora do projeto no Rio de Janeiro, com seus respectivos bolsistas; b) armazenamento dos dados de Alagoas do servidor da UFSC e disponibilização pública dos dados no site do Corpus de Libras (QUADROS et al., 2020)

O Inventário da Libras de Alagoas hoje está vinculado a outro projeto nacional, o de Documentação da Libras, também coordenado 
pela professora Dra. Ronice Müller de Quadros (UFSC), e encontra-se em fase de ajustes de transcrições (revisões) e tem impactado diretamente naquilo a que se propõe: um conjunto de dados teórico-metodologicamente estruturado para fins de pesquisa sobre a Libras. Dois dos nossos bolsistas surdos de iniciação científica, Sergio José da Silva e Ewerton Douglas Canuto de Albuquerque, fizeram TCC a partir de dados do corpus e acabaram de ingressar no mestrado no programa de Pós-graduação em Linguística e Literatura da UFAL, onde continuarão com suas pesquisas realizadas nos TCCs; Vanessa Lima Vidal, aluna de doutorado em Linguística da UFAL e professora da UFC, fará estudo sobre variação linguística usando dados dos corpora de Alagoas e do Ceará; Maiara Silva Santos, nossa bolsista de PIBIC está em fase de elaboração de TCC, sob orientação do professor colaborador Humberto Meira de Araújo Neto, também usando dados do Corpus; além disso, pelo menos mais cinco pesquisadores (do Letras-Libras ou do PPGLL/UFAL), não vinculados ao projeto do Corpus, utilizaram-se de dados dele para suas pesquisas.

Em suma, pode-se dizer que, para além da documentação da Libras em si, na variedade de Alagoas, o Inventário de Libras da Grande Maceió já encontra-se rendendo frutos no que concerne à pesquisa, de modo análogo ao que tem acontecido com em Florianópolis, onde pesquisadores envolvidos no Projeto e pesquisadores externos começam a lançar mão de dados do Corpus para o desenvolvimento de suas pesquisas. Destaque-se, ainda, as pesquisas que começam a ser feitas comparativamente com os dados de estados diferentes, como o fará Vanessa Lima Vidal, cuja investigação de doutorado implicará a comparação de dados de Alagoas e do Ceará. Outro ponto que salta aos olhos nesse tipo de projeto é a formação de novos pesquisadores no que tange a recursos técnicos, tecnológicos, teórico-metodológicos e éticos, principalmente dos alunos de graduação, por meio da Iniciação Científica

\subsection{INVENTÁRIO DA LIBRAS DO CEARÁ}

Esta parte tem a finalidade de apresentar a organização de um corpus de Libras, representativo do estado de Ceará, e está vinculado ao Projeto Inventário da Libras, da UFSC, considerado os mesmos parâmetros do projeto matriz. Este projeto está vinculado à proposta de trabalho e de expansão do Inventário Nacional da Libras da UFSC, projeto coordenado pela pesquisadora Ronice Müller de Quadros, a fim de tornar os dados comparáveis e mesmo de atender àquela proposta, ou seja, de formar um corpus de Libras do Brasil, adotaremos os mesmos procedimentos metodológicos daquele projeto. Desse modo, a grande Fortaleza integra o Inventário Nacional da Libras, juntamente com as demais capitais que hoje fazem parte do Projeto.

Da mesma forma que o projeto Inventário Nacional da Libras da UFSC, o Inventário da Libras da Região de Fortaleza coletará apenas os dados da Região Metropolitana de Fortaleza. Por esse motivo, trata-se de um "corpus representativo", visto que teremos a coleta da língua sinalizada da comunidade surda de uma das regiões do estado do Ceará. A Região Metropolitana de Fortaleza (CE) foi atualizada recentemente pela Lei complementar No 180, de 18 de julho de 2018, e é composta por 19 municípios, conforme a figura 3. Futuramente, pretende-se ampliar a coleta para outras regiões do Estado. 


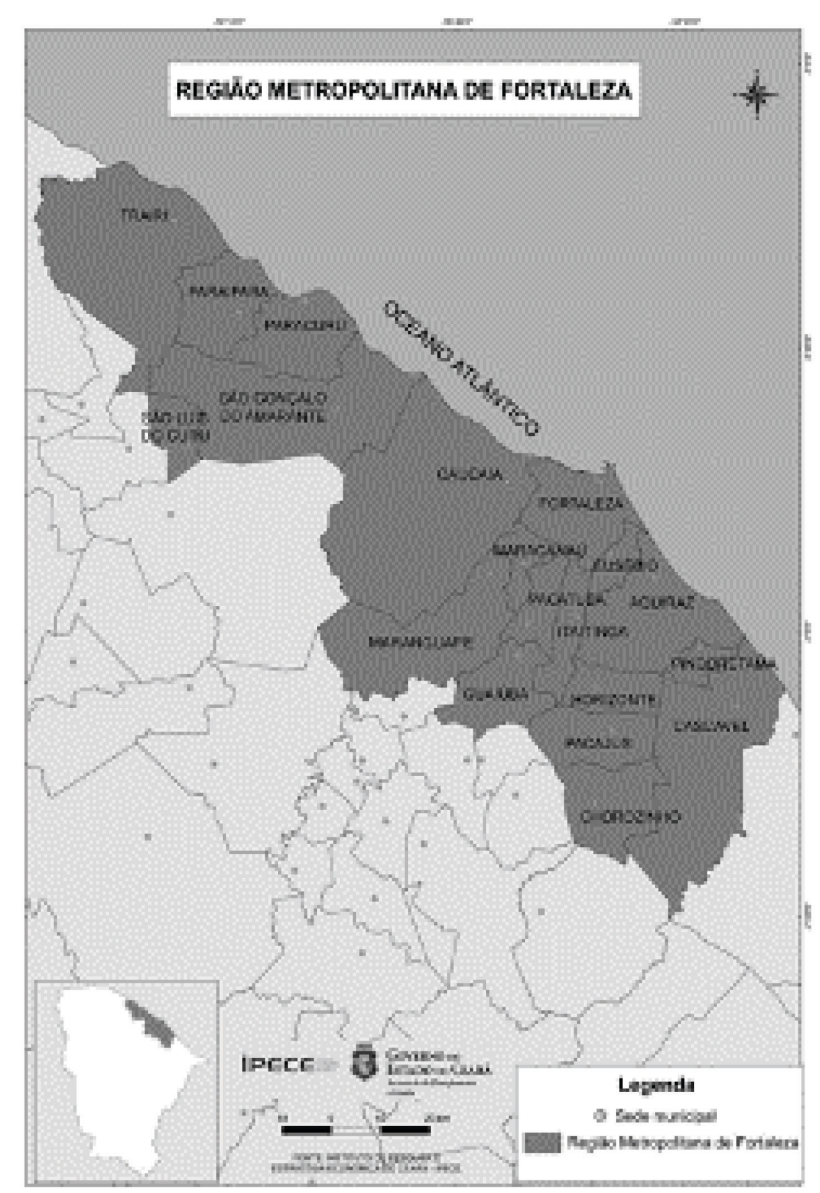

Figura 3: Mapa da Região Metropolitana de Fortaleza - Ceará

Fonte: Ceará em mapas (2020)

Com a implantação do curso de Letras-Libras: licenciatura, em 2013, pela Universidade Federal do Ceará (UFC), espera-se que o ensino em nível superior, a extensão e a pesquisa façam parte desse importante campo de estudo - a Libras, desenvolvendo pesquisas na área de língua de sinais, especialmente, da Libras. Atualmente na UFC, o curso Letras Libras é formado por 11 professores surdos e 8 professores ouvintes que desenvolvem atividades de ensino, pesquisa e extensão na Libras. Embora existam projetos de pesquisa no curso, há uma carência muito grande no estado do Ceará de documentação da Libras para fins de pesquisa e produção de material didático que enfoquem as variações linguísticas da Libras utilizadas por surdos no estado.

A sede do projeto está no curso de Letras Libras, do Departamento de Letras Libras e Estudos Surdos (DELLES), do Centro de Humanidades (CH), da UFC, na cidade de Fortaleza, onde será realizado a coleta, armazenamento e transcrição dos dados. O curso de Letras Libras possui 19 professores efetivos, sendo que 5 deles atuaram diretamente no projeto Inventário da Libras da Região de Fortaleza; há também professor parceiro na Universidade de Fortaleza (UNIFOR), uma professora da Universidade Estadual do Ceará (UECE) e um professor da Universidade Federal do Rio Grande do Sul (UFRGS) colaborando com a execução do projeto. Além do mais, o curso de Letras Libras da UFC possui 97 alunos, sendo 36 alunos surdos (dados de 2020.1), dentre os quais foram 2 selecionados bolsistas (uma pelo projeto de extensão e uma pelo projeto do CNPq) para atuar no projeto.

Os recursos e o material de equipamento para a montagem do estúdio da UFC foram oriundos de duas fontes. Inicialmente, os recursos são provenientes do projeto ao qual se vincula em parceria com o projeto matriz, coordenado pela Profa. Ronice de Quadros, da UFSC. A verba do CNPQ contemplou 4 câmeras de vídeo, 6 cartões de memória com 32GB, 3 tripés e um HD para armazenamento externo de 10TB e ainda uma bolsa discente por 36 meses. Outra parte dos equipamentos e recursos foi concedido pela UFC com o apoio da Pró-Reitoria de Pesquisa e Pós-Graduação, no qual foi obtido 3 computadores e dois kits de iluminação, como também uma bolsa discente pela Pró-Reitoria de Extensão durante três anos consecutivos. Ainda pela UFC, a Secretaria de Acessibilidade nos deu apoio com recursos humanos na instalação e manutenção do estúdio, com os serviços de um técnico em TI 
e um técnico de edição de vídeos. O Centro de Humanidades da UFC cedeu uma sala para abrigar o estúdio, que divide espaço com um Laboratório de Informática, próximo à área do Curso de Letras Libras. Foram necessários recursos e apoio de diferentes instituições e setores para a organização completa do projeto e do estúdio de gravação.

O Inventário da Libras do Ceará começou a organizar suas atividades no primeiro semestre de 2018, mas projeto estava sendo já proposto anteriormente em parceria com a Universidade Federal de Santa Catarina para submetê-lo a um edital do CNPq, que foi aprovado em 2017. Até o momento foram realizadas orientações e planejamento dos trabalhos junto à equipe que contou com a apresentação sobre Corpus da Libras: Conhecendo o Inventário Nacional para todos alunos de curso de Letras Libras e os demais interesses no evento de 24 de abril de 2018 como comemoração de Lei da Libras. Ainda em 2018, foi realizado o primeiro treinamento como Formação do Inventário Nacional da Libras - UFSC, em Florianópolis, no período de 11 a 13 de junho, juntamente com outros pesquisadores da UFAL, UFT e INES. No treinamento, também recebemos os materiais e equipamento cedidos pela UFSC/CNPq. Em novembro de 2018, a emenda que inclui a Universidade Federal do Ceará foi aprovada pelo Comitê Ética em Pesquisa (CEP), na Plataforma Brasil, na Universidade Federal de Santa Catarina. Em 2019, tivemos uma apresentação do Pôster do nosso trabalho do Congresso de ABRALIN 50 - XI Congresso Internacional da ABRALIN, no período de 05 a 08 de maio de 2019 e participamos do Encontro Nacional de Documentação da Libras, para Formação e Validação do Inventário Nacional da Libras, realizado na Universidade Federal de Alagoas - UFAL, em Maceió, no período de 13 a 14 de maio de 2019. Foi discutido a validação de ID glosas para estabelecer um padrão nacional para a transcrição dos dados no ELAN, juntamente com outros pesquisadores da UFSC, UFAL, UFT e INES. Neste ano de 2019, conseguimos concluir a organização do estúdio para realizar as filmagens que contaram com equipamentos da própria universidade e equipamentos do projeto de Documentação da Libras, com financiamento do CNPQ (\# 440337/2017-8). Também, realizamos o treinamento sobre as filmagens no estúdio do projeto, ministrado pelos alunos bolsistas da UFAL, que foram convidados especialmente para a oficina de Inventário de Libras, falando sobre sua experiência da UFAL, na Universidade Federal do Ceará. O treinamento aconteceu nos dias 11 a 13 de novembro de 2019. Foi realizada a testagem de gravação no estúdio e também foram dadas orientações sobre prática das filmagens. Também os 3 alunos bolsistas da UFAL ministram palestras sobre o projeto do inventário de Alagoas para alunos do Curso de Letras Libras na UFC.

Após a alocação do espaço físico para a montagem do estúdio de gravação, iniciamos os testes da coleta (ver figura 4). Iniciamos então a identificação dos informantes. Os dois bolsistas filmaram o TCLE do projeto, a fim de adequá-lo às variações linguísticas do estado do Ceará. Os instrumentos de coleta de dados também foram adaptados de acordo com as especificidades culturais do Ceará. As filmagens terão continuidade em 2020. Além disso, estamos ajudando na transcrição dos dados do projeto da Inventário da Alagoas, da Universidade Federal de Alagoas (UFAL).

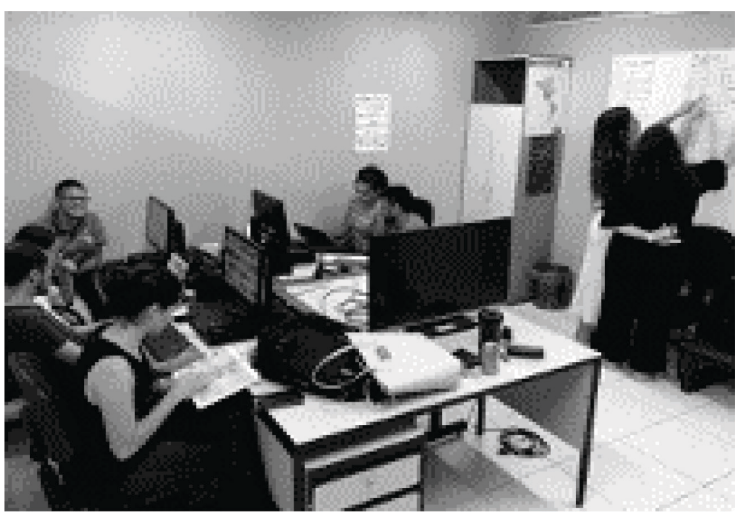

Sala da Reunião, edição de vídeos e transcrição dos dados

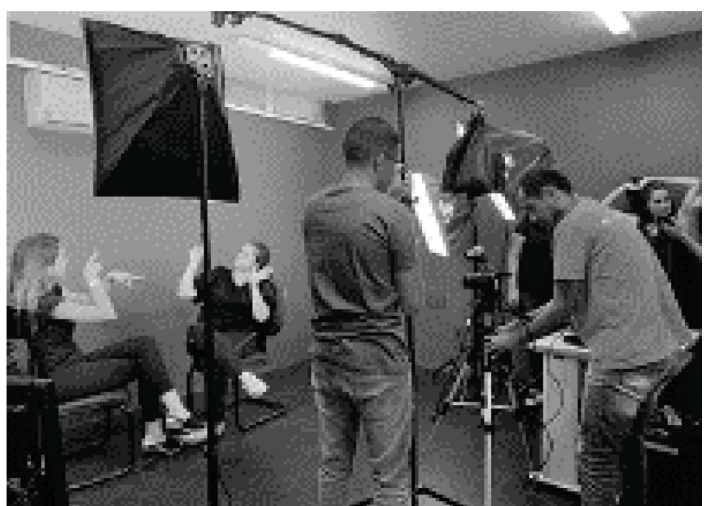

Sala do estúdio de gravação para coleta de dados

Figura 4: Sala exclusiva do projeto de Inventário da Libras: Fortaleza - Ceará

Fonte: os autores

Ainda que o Inventário de Libras do Ceará não tenha iniciado a coleta de dados, interrompida pela pandemia, já foram agendados com alguns informantes as entrevistas que devem acontecer após terminar o período de quarentena devido ao COVID-19. Depois 
da coleta de dados, a última etapa será a transcrição dos dados e a realização das pesquisas voltadas para o inventário da Libras.

A partir disso, o Inventário da Libras do Ceará, assim como o Inventário de Libras de Alagoas e do Tocantins, integrarão a Documentação de Libras, por meio do Corpus de Libras, no Portal de Libras organizado de forma acessível e didática para pesquisadores, professores, tradutores, intérpretes de língua de sinais utilizarem como recurso e fonte de pesquisa.

Rodrigo Nogueira Machado - professor da UFC e coordenador do projeto

Kátia Lucy Pinheiro - professora da UFC e pesquisadora do projeto

Vanessa Lima Vidal Machado - professora da UFC e pesquisadora do projeto

Marcus Weydson Pinheiro - professor da UFC e responsável pelas filmagens e edição dos vídeos do projeto

Patrícia Araújo Vieira - professora da UFC e pesquisadora do projeto

Willer Cysne Vasconcelos - professor da UNIFOR, pesquisador surdo local e líder da comunidade surda

Diná Souza da Silva - professora da UECE e pesquisadora do projeto

Marcelo Lúcio Correia de Amorim - professor da UFRGS e responsável pelos armazenamentos de dados do projeto

Cleyton Costa - bolsista de iniciação científica do CNPq e aluno do curso de Letras Libras

Amanda de Moura Barreto - bolsista de extensão da PREX/UFC - aluna do curso de Letras Libras.

\subsection{INVENTÁRIO DA LIBRAS DO TOCANTINS}

Esta seção apresenta o desenvolvimento do projeto Inventário da Libras da Região de Palmas - Tocantins. Nesse sentido, o Inventário da Libras no Tocantins supre uma necessidade de identificação, reconhecimento, valorização e documentação da língua brasileira de sinais, em particular as variantes em uso no estado do Tocantins. Além da documentação da Libras no Tocantins, análises com dados do corpus da Libras estão sendo desenvolvidas, a fim de oportunizar mais estudos linguísticos da Libras não só no estado, mas também no cenário nacional. Nesse sentido, análises das variantes locais, bem como análises comparativas com os dados do inventário de outros estados brasileiros contribuem qualitativamente e quantitativamente para a analisar aspectos linguísticos da língua brasileira de sinais.

Considerando que o projeto do Inventário da Libras da Região Metropolitana de Palmas - TO está vinculado a um projeto maior - Inventário Nacional da Língua Brasileira de Sinais, da UFSC, seus objetivos são os mesmos utilizados pelo projeto matriz, devidamente adaptados à realidade do Estado do Tocantins. O Inventário da Libras da Região de Palmas tem por finalidade criar um corpus da Libras representativo do estado do Tocantins e está vinculado ao Projeto Inventário Nacional da Língua Brasileira de Sinais, da UFSC, chamado de projeto matriz, coordenado pela Profa. Dra. Ronice Müller de Quadros. Nesse sentido, esse projeto é uma replicação do Inventário Nacional da Língua Brasileira de Sinais no Estado do Tocantins, conforme prevê o projeto matriz. Por esta razão, serão adotados os mesmos procedimentos metodológicos daquele projeto, a fim de se comparar os dados coletados no Estado do Tocantins com os dados de corpora de outros Estados brasileiros.

Da mesma forma que o projeto Inventário Nacional da Língua Brasileira de sinais da UFSC, o Inventário da Libras da Região de Palmas coletará apenas os dados da Região Metropolitana de Palmas. Por esse motivo, trata-se de um "corpus representativo", visto que teremos a coleta da língua sinalizada da comunidade surda de algumas as regiões do Tocantins. A Região Metropolitana de Palmas (TO) foi criada pela Lei Estadual № 2.824, de 30 de dezembro de 2013. A região metropolitana de Palmas é composta por 16 municípios $^{3}$, conforme a figura 5. Futuramente, pretende-se ampliar a coleta para outras regiões do Estado.

${ }^{3}$ Os municípios que integram a região metropolitana de Palmas são os seguintes: Palmas, Aparecida do Rio Negro, Barrolândia, Brejinho de Nazaré, Fátima, Ipueiras, Lajeado, Miracema do Tocantins, Miranorte, Monte do Carmo, Oliveira de Fátima, Paraíso do Tocantins, Porto Nacional, Pugmil, Silvanópolis e Tocantínia. 


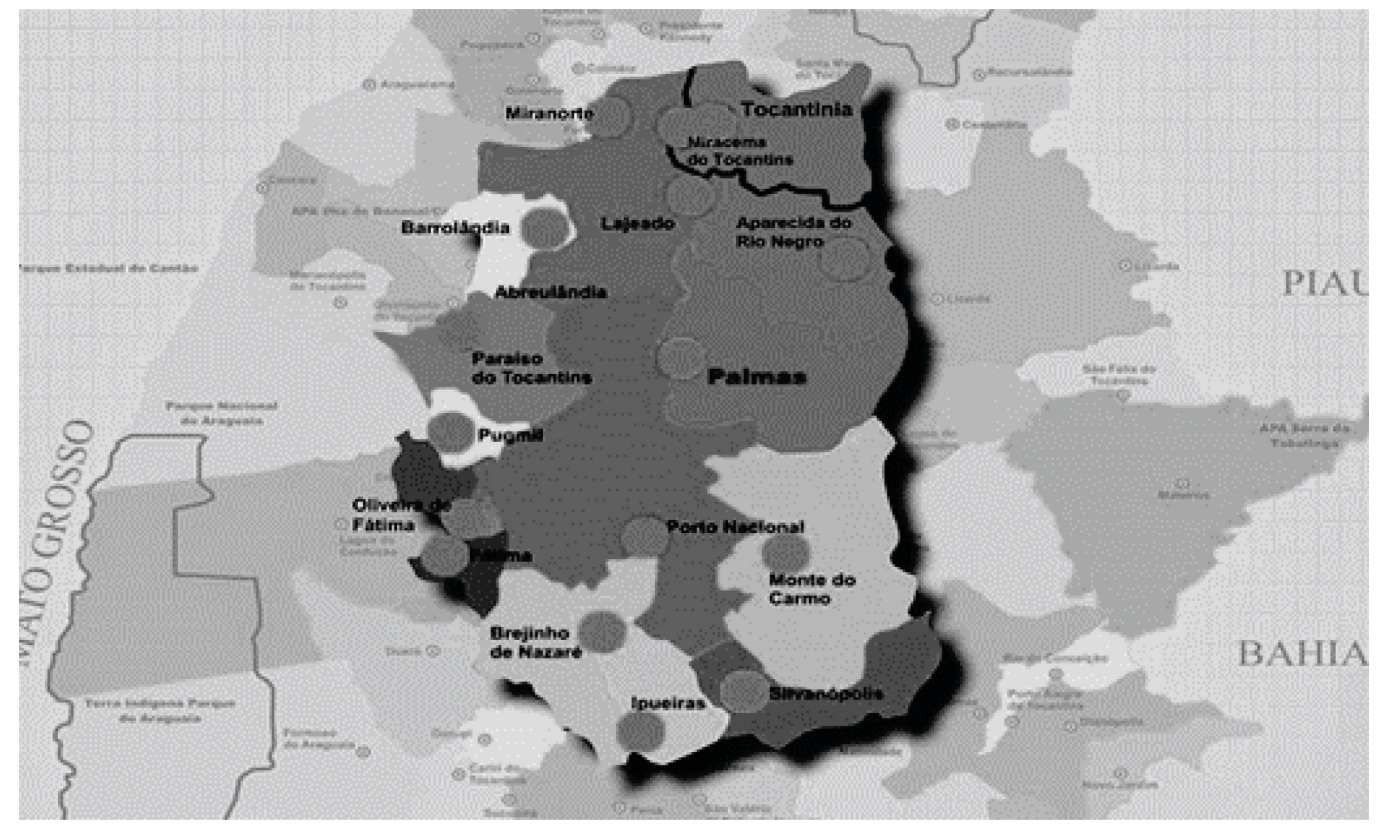

Figura 5: Mapa da Região Metropolitana de Palmas - Tocantins

Fonte: Bastos (2014)

\begin{abstract}
A Universidade Federal do Tocantins possui atualmente doze professores surdos efetivos que, articulados à comunidade surda local, contribuem para a implementação de políticas frente às demandas legais que ora se apresenta no cenário Estadual e municipais. A sede do projeto é no Curso de Letras: Libras, da Universidade Federal do Tocantins, na cidade de Porto Nacional. A escolha da cidade de Porto Nacional para a realização da coleta, armazenamento e transcrição dos dados se deve ao fato de o Curso de Letras: Libras da UFT ter sua sede na cidade de Porto Nacional, situada a $64 \mathrm{~km}$ da capital Palmas - TO. O curso de Letras: Libras possui nove professores surdos efetivos, os quais atuarão diretamente no projeto Inventário da língua brasileira de sinais da Região de Palmas - Tocantins. Esses nove professores surdos estão envolvidos na equipe do inventário, realizando a coleta de dados, a transcrição e validação dos dados.
\end{abstract}

O Inventário da Libras do Tocantins iniciou suas atividades em 2018, com a elaboração do projeto e aprovação no comitê de ética. Além disso, de 11 a 13 de junho de 2018, foi realizado o primeiro treinamento do Inventário da Libras na UFSC. Participaram seis professores do Curso de Letras: Libras, além de um bolsista de PIBIC-CNPq, juntamente com outros pesquisadores da UFAL, UFC e INES.

Entre os meses de novembro de 2018 a março de 2019, houve a reforma de uma sala para abrigar as atividades do projeto. São 2 espaços físicos do Inventário da Libras: um para coleta de dados e outro para a transcrição dos dados. De abril a agosto de 2019, foram realizadas adaptações e a pintura da sala da coleta de dados. A sala possui cor azul turquesa, como percebemos na figura 6 . Além disso, foram instaladas 4 câmeras e 2 monitores para envio dos estímulos linguísticos da coleta de dados, a partir de 2 notebooks instalados na sala de transcrição. 


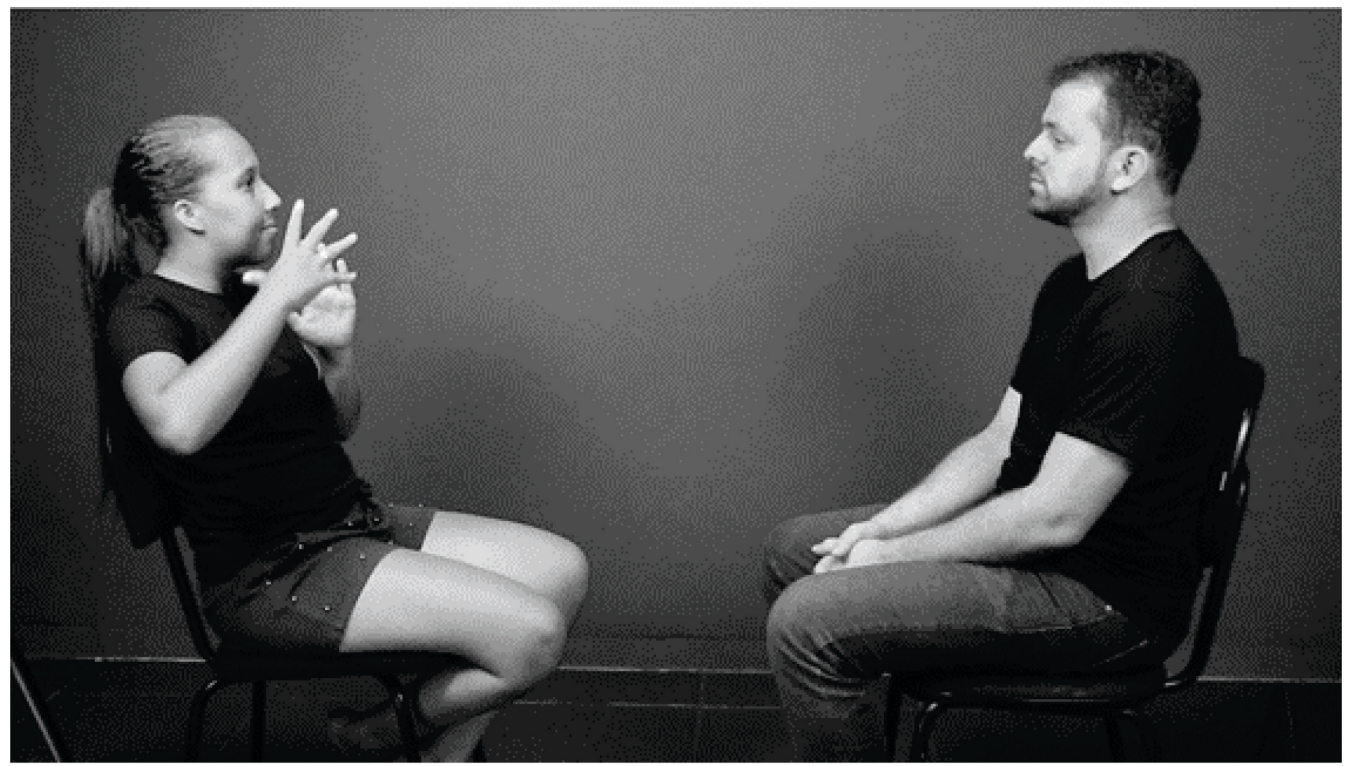

Figura 6: Entrevista na Coleta de Dados do INDL-Libras de Palmas - Tocantins

Fonte: Coleta de Dados do Inventário da Libras do Tocantins, tomada da câmara 3. À esquerda está a informante 1, da dupla 1, grupo 1; à direita, o entrevistador, surdo pesquisador local

Assim, após pesquisa e discussão com o grupo de pesquisadores do Corpus da Libras do Tocantins, escolhemos um dos pesquisadores do Corpus: Renato Jefferson Bezerra Leão. Ele tem 30 anos, é natural de Petrolina - PE, professor universitário de Libras e escrita de sinais do Curso de Letras: Libras, da UFT/Campus de Porto Nacional. Ele atende os requisitos propostos no projeto inicial em sua totalidade: reside em Palmas e convive com a comunidade surda local por 10 anos, é articulado e extrovertido. Como assistente de identificação dos participantes e das filmagens, foi selecionada Roselba Gomes de Miranda. Ela tem 50 anos, é natural de Balsas - MA, professora universitária de Libras do Curso de Letras: Libras da UFT/Campus de Porto Nacional, vive há mais de 10 anos no estado e circula na comunidade surda da região de Palmas com muita desenvoltura. Além disso, os dois pesquisadores filmaram o TCLE do projeto, a fim de adequá-lo às variações linguísticas do estado do Tocantins. Os instrumentos de coleta de dados também foram adaptados de acordo com as especificidades culturais do Tocantins.

Em novembro de 2019, o Inventário de Libras do Tocantins iniciou a coleta de dados. Visto que a coleta ainda está em andamento, nem todas as cidades tiveram surdos entrevistados. Foram selecionados informantes surdos de Palmas, Porto Nacional, Miracema do Tocantins, Paraíso do Tocantins e Silvanópolis. Considerando que algumas cidades possuem população pequena de surdos, as possibilidades de constituir uma dupla de surdos da mesma cidade são mais restritas. Por isso, ainda não foi possível incluir outras cidades.

O próximo passo, após a finalização da coleta, é a transcrição dos dados e a realização das pesquisas voltadas para o inventário da Libras. Dentre as pesquisas em andamento, há duas pesquisas que já estão analisando dados do Inventário da Libras do Tocantins. Uma pesquisa de sentenças complexas em Libras, em particular as estruturas hipotáticas em Libras. É realizada pelos docentes do curso de Letras: Libras Carlos Ludwig e Bruno Carneiro, com a participação do bolsista Cleysson Wender Pires. A outra pesquisa foca a variação no léxico da Libras, com dados da coleta da lista Swadesh. É realizada por Carlos Ludwig e o bolsista Lucas Fagundes.

Integrantes do Inventário de Libras do Tocantins

Carlos Roberto Ludwig - Coordenador e Pesquisador do projeto

Alanna Alencar de Araújo Cruz - Professora da UFT e Pesquisadora do projeto

Bruno Gonçalves Carneiro - Professor da UFT e Pesquisador do projeto

Cleysson Wender Fernandes Pires - Bolsista do CNPq e aluno do Curso de Letras: Libras

Cristiano Pimentel Cruz - Professor da UFT e Pesquisador do projeto

Felipe de Almeida Coura - Professor da UFT e Pesquisador do projeto

Gabriela Otaviani Barbosa - Professora da UFT e Pesquisadora do projeto 
Gesica Suellen Sobrinho Costa - Professora da UFT e Pesquisadora do projeto

José Ishac Brandão El Khouri - Professor da UFT e Pesquisador do projeto

Lucas Fagundes - Bolsista do CNPq e aluno do Curso de Letras: Libras

Maria Inez Souza Maia - Professora da UFT e Pesquisadora do projeto

Renato Jefferson Bezerra Leão - Pesquisador Surdo Local, Professor da UFT e pesquisador do Projeto

Rodrigo Augusto Ferreira - Professor da UFT e Pesquisador do projeto

Roselba Gomes de Miranda - Professora da UFT e Pesquisadora do projeto

Vinícius Hidalgo Pedroni - Professor da UFT e Pesquisador do projeto

\section{CONSIDERAÇÕES FINAIS}

O Inventário Nacional de Libras iniciado no estado de Santa Catarina começa a ter uma dimensão nacional ao ser replicado em mais três estados brasileiros: Alagoas, Ceará e Tocantins. O objetivo do projeto é ainda atingir todos os estados brasileiros. Estamos ampliando a composição deste inventário gradativamente, por meio de recursos locais e recursos do CNPQ. A proposta é termos um registro de produções em Libras de todo o território brasileiro com dados comparáveis para análises da Libras que evidenciam a diversidade sociolinguística manifestada por meio da sua estrutura. Mesmo sendo uma língua nacional, a língua reflete aspectos sociolinguísticos específicos de cada comunidade surda brasileira que precisam ser devidamente registrados e estudados. A partir deste mapeamento inicial, já podemos começar a verificar a riqueza linguística e cultural da Libras por meio de práticas linguísticas comuns.

O Inventário Nacional de Libras consolida a Libras como língua que compõe o patrimônio da diversidade linguística brasileira. As pesquisas desdobradas deste Inventário Nacional fortalecem a valorização da Libras, assim como subsidiam as políticas linguísticas brasileiras e a produção em Libras que pode ser usada para fins de pesquisa e para fins educacionais.

Além da documentação da Libras propiciada por esse projeto, é importante destacar o impacto que ele tem na formação de novos pesquisadores. Documentar uma língua é, em última instância, também tomar decisões sobre o quê e como fazer nos momentos de coleta, transcrição e armazenamento dos dados. Essas ações demandam conhecimentos linguísticos (teóricos e práticos - uso da língua), técnicos, tecnológicos, éticos e metodológicos que impactam na formação dos envolvidos no projeto, quer pesquisadores iniciantes, como é o caso dos alunos de graduação, quer de pesquisadores mais experientes, como os alunos de pós-graduação ou professores mais experientes em pesquisas. As pesquisas envolvendo línguas de sinais no mundo ainda são bastante recentes, incluindo-se aí a constituição de corpora dessas línguas, o que sugere dois pontos igualmente relevantes: i) a necessidade de formação de pesquisadores na área; ii) a documentação e descrição das línguas de sinais certamente têm muito a contribuir com a tradição de estudos de línguas orais.

Por fim, esperamos, com este trabalho coletivo, contar com outros estados integrando o Inventário Nacional da Libras a partir deste projeto, a fim de que possamos ter uma amostra mais representativa da Libras usada no Brasil, em face das variações, mas também daquilo que lhe é padrão.

\section{AGRADECIMENTOS}

Este trabalho foi possível parcialmente pelos recursos do Conselho Nacional de Desenvolvimento Científico e Tecnológico - CNPQ (\# 440337/2017-8), assim como parcialmente por recursos do Instituto do Patrimônio Histórico e Artístico Nacional (IPHAN), do Ministério da Cultura, em parceria com o Instituto de Políticas Linguísticas (IPOL). 


\section{REFERÊNCIAS}

BASTOS, P. Região Metropolitana de Palmas reúne 15 municípios e 430 mil moradores. SECOM, TO, 14 jan. 2014. Disponível em: https://secom.to.gov.br/noticias/regiao-metropolitana-de-palmas-reune-15-municipios-e-430-mil-moradores-174518/. Acesso em: 20 nov. 2020.

CEARÁ EM MAPAS. Região metropolitana de Fortaleza. Disponível em: http://www2.ipece.ce.gov.br/atlas/capitulo1/11/125x.htm. Acesso em: 20 nov. 2020.

CHEN PICHLER, D. et al. Conventions for sign and speech transcription of child bimodal bilingual corpora in ELAN. Language, Interaction and Acquisition. v.1, 2010, p. 11-40, 2010.

CRASBORN, O.; VAN DER KOOJI, E.; MESCH, J. European cultural heritage online (ECHO): Publishing sign language data on the internet. In: CONFERENCE ON THEORETICAL ISSUES IN SIGN LANGUAGE RESEARCH, 8., Barcelona, 2004. Proceedings... Barcelona: ECHO, 2004. p. 535-562.

EFTHIMIOU, E.; FOTINEA, S-E. Creation and annotation of a Greek Sign Language corpus for HCI. Universal access in human computer interaction: coping with Diversity. In: INTERNATIONAL CONFERENCE ON UNIVERSAL ACCESS IN HUMANCOMPUTER INTERACTIONS, 4., Beijing, 2007. Proceedings... Beijing: ILSP, 2007. p. 1-10.

IPHAN. Ministério da Cultura. Guia de Pesquisa e Documentação para o INDL, 2012. http://portal.iphan.gov.br/uploads/ckfinder/arquivos/Guia\%20de\%20Pesquisa $\% 20 \mathrm{e} \% 20$ Documenta\%C3\%A7\%C3\%A3o\%20para \%20o\%20INDL\%20-\%20Volume\%201.pdf

HANKE, T. (ed.). ViSiCAST Deliverable D5-1: interface definitions. 2000. Disponível em: http://www.visicast.co.uk/members/milestones/ViSiCASTD5-1.pdf. Acesso em: 14 mar. 2006.

LEESON, L.; SAEED, J.; BYRNE-DUNNE, D. Moving heads and moving hands: Developing a digital corpus of Irish Sign Language. The 'Signs of Ireland' corpus development project. 2006. Disponível em: http://webird.tcd.ie/bitstream/2262/1597/1/ITT+paper+vfinal.pdf. Acesso em: 13 mar. 2009.

LEITE, T. A segmentação da língua de sinais brasileira (libras): um estudo lingüístico descritivo a partir da conversação espontânea entre surdos. 2008. Tese (Doutorado) - Universidade de São Paulo, São Paulo, 2008.

LEITE, T. de A.; QUADROS, R. M. de. Línguas de sinais do Brasil: reflexões sobre o seu estatuto de risco e a importância da documentação. In: Estudos da Língua de Sinais. v. 2. Florianópolis: Editora Insular, 2014. p. 15 - 27.

LIBRAS. Portal de Libras. Disponível em: https://portal.libras.ufsc.br. Acesso em: 25 jan. 2021.

LIBRAS. Portal de Libras. Disponível em: https://libras.ufsc.br/. Acesso em: 25 abr. 2020.

MILLER, C. Some reflections on the need for a common sign notation. Sign Language and Linguistics, v. 4, n.1/2, p.11-28, 2001.

QUADROS, R. M. de et al. Corpus de Libras. 2020. Disponível em: http://corpuslibras.ufsc.br/. Acesso em: 17 fev. 2020.

QUADROS, R. M de. Documentação da Libras. In: SEMINÁRIO IBERO-AMERICANO DE DIVERSIDADE LINGUÍSTICA, 2014, Foz do Iguaçu. Brasília: IPHAN - Ministério da Cultura. vol. 1. 2016. p. 157-174.

QUADROS, R. M. et al. Língua Brasileira de Sinais: patrimônio linguístico brasileiro. Florianópolis: Editora Garapuvu, 2019. 
SCHEMBRI, A. C. The British Sign Language corpus project: open access archives and the observer's paradox. In: CRASBORN, O.; EFTHIMIOU, E.; HANKE, T.; THOUTENHOOFD, E. D.; ZWITSERLOOD, I. Proceedings of the Construction and exploitation of sign language corpora workshop, Marrackech, 2008. p. 165-169.

UFSC. Libras. SignBank da Libras, 2020. Disponível em: http://signbank.libras.ufsc.br/.Acesso em: 20 nov. 2020.

WIKIPEDIA. Imagem de Maceió, $2020 . \quad$ Disponível

https://pt.m.wikipedia.org/wiki/Ficheiro:Regi\%C3\%A3o Metropolitana de Macei\%C3\%B3 (AL).svg.Acesso em: 20 nov. 2020.

\section{() (1) $\circledast \circledast$}

Recebido em 24/09/2020. Acesso em 02/12/2020. 